\title{
Size-assortative mating in the absence of mate choice
}

Barbara Taborsky (barbara.taborsky@iee.unibe.ch)

Luzia Guyer (luzia.guyer@iee.unibe.ch)

Michael Taborsky (michael.taborsky@iee.unibe.ch)

\section{Approved by}

Ulf Dieckmann

Leader, Evolution and Ecology Program

June 2010

Interim Reports on work of the International Institute for Applied Systems Analysis receive only limited review. Views or opinions expressed herein do not necessarily represent those of the Institute, its National Member Organizations, or other organizations supporting the work. 
$6 \quad{ }^{1}$ Behavioural Ecology, Institute of Ecology and Evolution, University of Bern, Switzerland

$7 \quad{ }^{2}$ Evolution \& Ecology Program, IIASA, Austria

8

9 Running headline: Mechanisms of size-assortative mating

10

11

12

13

14

15 Correspondence:

16 Barbara Taborsky

17 Department of Behavioural Ecology

18 Institute of Zoology

19 University of Bern

20 Wohlenstrasse 50A

21 CH-3032 Hinterkappelen

$22 \quad$ Switzerland

23

$24 \quad$ barbara.taborsky@esh.unibe.ch

25 phone: +41316319157

26

27 Postal address of L. Guyer and M. Taborsky: same as correspondence address

28

29 Word count: 7667

30 
31 Size-assortative mating is one of the most common mating patterns in nature. Nevertheless, the 32 underlying behavioural mechanisms have received little attention. Assortment is typically 33 assumed to result from mate choice, which can be coupled with differences in competitive 34 potential. We investigated the behavioural mechanisms underlying size-assortative mating in a monogamous, biparental goby cichlid, where mutual mate choice should be expected. We performed three field experiments with females and males of Eretmodus cyanostictus to test for the existence of mate preferences in general and with regard to size, (i) a sequential presentation of differently sized potential partners, (ii) a removal of partners combined with surveillance until re-pairing with a new partner, and (iii) the simultaneous release of new and original partners on the experimental territories. In the removal experiment, we found evidence for weak preferences

41 for large partners relative to own size and to the original partner's size, but pairs were formed 42 irrespective of these preferences. The ecological importance of being paired appears to reduce 43 choosiness and to override mate preferences. Territory ownership was quickly decided by aggressive interactions between original and new partners, and in both sexes the larger contestant won and was immediately accepted as partner by the resident. Our results suggest that strong

46 intra-sexual competition can be a powerful promoter of size-assortative mating even in the absence of active mate choice.

KEYWORDS: assortative mating, size, mating preferences, mate choice, intra-sexual competition, monogamy, biparental care, cichlids, Eretmodus cyanostictus Size-assortative mating defined as a positive correlation between the body sizes of male and

53 female partners ranks among the most common mating patterns in nature (Ridley 1983, Crespi 54 1989, Rowe \& Arnqvist 1996). It has been described in a wide range of taxa, including flatworms 55 (Vreys \& Michiels 1997), molluscs (e.g. Cruz et al. 2004), annelids (Michiels et al. 2001), 
arthropods (Crespi 1989), fish (e.g. Kolm 2002, Olafsdottir et al. 2006), amphibians (Arak 1983), reptiles (Olsson 1993, Shine et al. 2001), birds (Delestrade 2001, Helfenstein et al. 2004) and mammals (Preston et al. 2005). Surprisingly, the behavioural mechanisms leading to sizeassortative mating have been explored only rarely (Rowe \& Arnqvist 1996), which hampers our understanding of evolutionary mechanisms underlying this mating pattern. Most often sizeassortative mating is thought to result from mate choice for large size by one or both sexes (Crespi 1989, Harari et al. 1999). A preference for large partners is often coupled with a sizedependent competitive potential allowing larger individuals to obtain the preferred partners by excluding smaller, physically inferior competitors (Crespi 1989, Olsson 1993, Harari et al. 1999). Mating with large females is beneficial if these are more fecund (Roff 1992) or produce larger eggs (Kolm 2001), while females may benefit from mating with large males if the latter are less likely to be sperm-limited (MacDiarmid \& Butler 1999), or better able to defend or provide resources for offspring (Gagliardi-Seeley \& Itzkowitz 2006), or contribute 'good genes' for offspring (Riechert \& Johns 2003).

0
case small individuals should reject large potential partners even if these would be willing to mate. 'Prudent' mate choice should evolve when mating with a large partner bears costs for small individuals, which are not outweighed by size-related advantages (Härdling \& Kokko 2005). For example, mating with a larger partner may increase the risk of predation (Michiels et al. 2001) or of asymmetric exploitation (Vreys \& Michiels 1997), or intra-sexual competition may make it too costly for small, inferior individuals to strive for the best available option (Alatalo et al. 1992, Shine et al. 2001). 
In the study of size-assortative mating we must distinguish between mating preferences

81 for a certain partner size and the process that actually produces the observed size assortment.

82 Other factors influence mate choice besides preferences, such as the costs of choice, the 83 availability of potential mates (Jennions \& Petrie 1997) and, most importantly, intra-sexual competition of potential partners and their complex interactions with mating preferences (reviewed in Wong \& Candolin 2005). Mechanisms that do not involve mate choice have received little attention so far, and appear to apply only under limited conditions. Size assortment of mates (i) may be a by-product of a correlated distribution of male and female body sizes in space (Johannesson et al. 1995) or time (Miyashita 1994), or (ii) may arise if mechanical constraints render mating between mismatched partners inefficient or impossible (Crespi 1989, Brown 1993, Otronen 1993).

We investigated the behavioural mechanisms of pair formation in the long-term monogamous, biparentally mouthbrooding cichlid Eretmodus cyanostictus from Lake Tanganyika, in which sizes of male and female partners are highly correlated (Morley \& Balshine 2002; this study, Fig. 1). In this species, mutual mate choice should be favoured by selection, as offspring survival depends greatly on biparental care (Kokko \& Johnstone 2002). A single E. cyanostictus cannot brood the clutch for the entire incubation period of three weeks (Grüter \& Taborsky 2004). Both pair partners contribute a substantial share to the parental care duties. In E. cyanostictus, mutual choice for large size might be expected because larger females are more fecund (Morley 2000), large females and males can hold larger clutch volumes in their mouth (Morley 2000, M. Steinegger \& B. Taborsky, unpubl. data), and large males may be more efficient in defending the territory (both sexes defend the territory jointly, but males are on average bigger and take a greater share of defence; Morley 2000). Alternatively, both sexes might prefer a partner of matching size, if they run the risk to be expelled from their territory by larger 
competitors when having a large and too attractive partner ('prudent mate choice', Härdling \&

106 Kokko 2005). In E. cyanostictus, both mechanical mating constraints and heterogeneous spatio-

107 temporal distributions of size classes can be excluded as potential causes of size-assortative 108 mating.

110 We conducted three experiments in the field to investigate the relative importance of

111 mating preferences and intra-sexual competition for pair formation in E. cyanostictus; (i)

112 experimentally widowed individuals were given a choice between caged fish of defined sizes; (ii)

113 experimental widows ('residents') were allowed to interact with the natural range of unconfined

114 potential partners in the presence of natural levels of competition for partners and space; (iii)

115 during the latter experiment residents quickly paired up with a new partner; in a subsequent test

116 we released new and original partners simultaneously at the resident's territory to test for effects

117 of status (original or new partner) and size on ultimate pair formation.

As E. cyanostictus is a species with long-term monogamy, the loss of a partner should be

120 a critical event in the life history inducing extensive mate assessment before a new pair is formed.

121 Therefore, we expected to find clear evidence of mate preferences and expected these preferences

122 to ultimately influence pair formation. As this species mates size-assortatively, we expected mate

123 preferences to be size-dependent. Furthermore, we expected that larger individuals would obtain

124 preferred partners more easily due to size-dependent differences in resource holding potential.

\section{METHODS}

\section{Study Site and Species}


We conducted our experiment at the southern tip of Lake Tanganyika at Kasakalawe

131 Point $\left(8^{\circ} 46.849^{\prime} \mathrm{S}, 31^{\circ} 04.882^{\prime} \mathrm{E}\right)$ near Mpulungu, Zambia, between mid September and end of

132 November 2005. All data were obtained at water depths of 3.0 to $3.5 \mathrm{~m}$ using SCUBA diving.

E. cyanostictus pairs co-defend all-purpose territories along the rocky shores of the lake.

135 By far the most of territory defence is directed towards conspecifics, and males show more 136 defence behaviour than females (Morley 2000, p. 34). At a depth of 3m, territories at Kasakalawe

137 Point comprise an area of about $2.0 \mathrm{~m}^{2}$ (= median, Morley 2000) and contain up to three layers of 138 granite stones. E. cyanostictus feed almost exclusively on turf algae covering the stone surfaces, 139 and they use crevices between the stones as shelters. Brood care is strictly biparental. Females 140 brood the clutch for 7-10 days before transferring them to the male to be brooded for another 1214116 days, and the actual shares taken by each partner depend on the parents' energetic state 142 (Steinegger \& Taborsky 2007) and operational sex ratio (Grüter \& Taborsky 2005).

\section{General Field Methods}

To select experimental territories haphazardly we dived parallel to the coastline from a 146 defined starting point at a depth of $3 \mathrm{~m}$ and stopped every $4-6 \mathrm{~m}$. We observed the fish in front of 147 us until we roughly knew the boundaries of their territories, and then used the territory closest to 148 us as experimental territory. Pairs can be easily recognized by courtship behaviour, joint feeding 149 and joint defence against conspecifics (cf. Morley \& Balshine 2002). Experimental territories 150 were marked by numbered stones placed near the centre. Any stationary individual can be 151 identified by its unique pattern of light-blue, iridescent spots (Morley \& Balshine 2002). To catch 152 a fish we waited until it stayed motionless under a stone. Then we placed a tent-shaped, fine153 meshed net over the stone and coaxed the fish to swim into it by carefully lifting the stone. All 154 body size measurements were taken under water to minimize handling stress. We placed the fish 
on a framed measuring board with a 1-mm grid, adjusted it to the left and lower frames of the board and read its standard and total lengths to the nearest mm. We used total length (TL) as measure of body length for all analyses. None of the fish used in our experiments were mouthbrooding at the time of catching or during the course of the experiment.

\section{Presentation experiment}

In this experiment, we tested female preferences. Compared to males, females are more likely to discriminate between potential partners, as is it more difficult for males to find a new partner because of a biased sex ratio (see 'Results'). At the beginning of each of 10 trials we determined and marked an experimental territory, identified the territory owners by sketches of their individual colour spot patterns and estimated their sizes. We captured three males from an area at least $20 \mathrm{~m}$ away from the experimental territory (sex was confirmed by inspection of genital papilla) that were smaller $(\bar{x} \pm \mathrm{SD}=6.47 \pm 0.36 \mathrm{~cm}, \mathrm{~N}=10)$, similar $(7.26 \pm 0.39 \mathrm{~cm}, \mathrm{~N}=9)$ and larger $(8.33 \pm 0.48 \mathrm{~cm}, \mathrm{~N}=10)$ in size, respectively, than the male owner of the experimental territory, and we also caught the territorial male $(7.37 \pm 0.80 \mathrm{~cm}, \mathrm{~N}=10)$. We placed the four males in separate mesh cages a few metres away from the experimental territory. We waited for 10 min to allow the territorial female to recognize the absence of her partner. We considered this time span as adequate because territories are small, and females usually started to swim around in the entire territory and to inspect shelters soon after we caught the male. Then we presented the males sequentially in a randomly chosen order (the respective sequence of treatments was determined before each dive), and observed the female resident for $15 \mathrm{~min}$ (see below). Males were presented in a clear plexiglas tube of $15.0 \mathrm{~cm}$ length and an inner diameter of $8.2 \mathrm{~cm}$, which was closed on one end by a $1 \mathrm{~mm}$-mesh allowing for water exchange, and on the other end by a removable plastic lid. After all presentations were finished, we caught the territorial female to 
179 measure its size $(\bar{x} \pm \mathrm{SD}=6.54 \pm 0.49 \mathrm{~cm}, \mathrm{~N}=10)$, then we released all fish at the respective places 180 of their capture.

Behavioural recordings

We placed the tube with the male in the centre of the experimental territory and

184 immediately started a 15 -min behavioural recording. We continuously noted all behaviours by the 185 female or any other fish directed towards the tube, and every $30 \mathrm{~s}$ we estimated the female's 186 distance from the tube. Furthermore, we recorded the female's feeding rate, and any interactions 187 with other fish, and we noted behaviour of the male in the tube.

\section{Partner Removal and Release Experiments}

Removal experiment

We completed nine trials of male removals and ten trials of female removals. Another five trials had to be terminated prematurely - three times the resident left its territory at some stage after the removal of its partner, and two times the removed partners escaped from their holding cages and returned to their original territory before the end of the removal phase. We included these five trials in our analyses as far as possible.

We caught the pair member that we had designated beforehand to stay on the territory

198 (further called 'resident'), measured its standard and total lengths and marked it by excising half 199 of one dorsal fin ray to facilitate quick identification during focal observations. Then we released 200 the resident in a central shelter of its territory and left the territory undisturbed for 1-2 days before 201 removing its partner. 
All removals were done in the morning. We first recorded the behaviour of the resident

204 for 15 min (see 'Behavioural recordings'). Then we caught the pair member that had been 205 designated to be removed (the 'original partner') and put it into a mesh cage until its release. The 206 cage was equipped with four medium-sized stones (major axis approx. 15-20 cm) arranged in a 207 pyramid to form a high-quality shelter with several entrances. As stones were covered with turf 208 algae they also provided food for the caged fish. Each cage was checked for the well-being of its 209 inhabitant once a day. During these checks, fish either moved around in the cage while scraping 210 algae from stones, or they were using their shelter. Further 15-min behavioural recordings of the 211 resident were done (i) 45 min after capturing its partner, (ii) in the early and (iii) late afternoon of 212 the same day (separated by an interval of $2 \mathrm{~h}$ ) and (iv) in the morning of day 2 . If the resident had 213 not re-mated by that time, additional recordings were done in the afternoon of day 2 and, if it was

214 still single, also in the morning of day 3. A removal trial was terminated after the last recording 215 of this observation schedule.

\section{Release experiment}

During the first morning or afternoon dive after completion of a removal trial, we caught

219 the new partner, measured its length and caged it temporarily, while taking the resident's old 220 partner from its cage and measuring its length as well. Both fish were marked by fin clipping as 221 described above for quick identification. Then we released both fish ('new' and 'original partner') 222 in the centre of the territory simultaneously in two nearby shelters. We immediately did a 15 -min 223 behavioural recording, and we did a second recording either in the afternoon of the same day (if 224 the release was in the morning), or in the morning of the following day. The day after the end of 225 each release trial, we checked which individuals were present in the territory. At 12 territories we 226 made between 1 and 8 further checks on later days spread over a period of day 2 to day 37 after 
227 the end of the release experiment. No further partner changes were detected during these 228 additional checks.

Behavioural recordings

During 15-min behavioural observations we continuously recorded all social behaviours

232 (see Appendix 1) between the resident and any other fish. Together with the behaviour, we noted 233 whether it was shown by or towards the resident, or reciprocally by both fish, and we estimated 234 the difference between TL of conspecific visitors and residents in mm (the residents' TL was 235 measured before). We validated our estimates by first estimating and then measuring the TL of 9 236 new partners (mean deviation of measured $\mathrm{TL}=3.8 \%$ ). We noted any information available about 237 the identity of the other fish (e.g., whether it was a territory neighbour or an unknown 238 conspecific, or if it was another species). We counted the total number of feeding bites by the 239 resident per 15 min and recorded the time it was hiding and the time out of sight using two stop 240 watches. Whenever possible we also noted social interactions between the resident's partner and 241 other fish, even if the resident itself was not involved.

243 Definitions

244 Behaviour: Appendix 1 describes the behaviours recorded during the 15-min observations, 245 subdivided in three categories: contact behaviour, partner-directed behaviour and aggressive 246 behaviour.

248 Pair: We considered a conspecific to be a partner of a resident if it was fully tolerated on the 249 territory during one or more recordings, and if the two fish acted together repeatedly, that is they 250 showed mutual S-bends or courtship, they were seen feeding or hiding together, or they jointly 
251 defended the territory against other fish. This criterion was met by all original pairs before

252 partners were removed, and it was also applied for new partners.

254 Time to re-pairing: The time between removal of the old partner and pairing up of the resident 255 with a new partner. As re-pairing was not directly observed during the removal experiment, we 256 used the mean of the period between the last sighting of a resident being single and the first 257 sighting when it was together with a new partner as an estimate for the time of re-pairing. These 258 estimates include only the 13 daylight hours, as E. cyanostictus are inactive at night (B. 259 Taborsky, pers. obs.).

261 Sex: Male and female E. cyanostictus are monomorphic and can only be told apart 262 unambiguously by inspection of their genital papilla after capture. Males are on average larger 263 than females, but the size distributions overlap. For data analysis we assigned a sex to each fish 264 that had entered a territory during the behavioural recordings to determine the number of 265 potential partners. We used a criterion based on the size distributions of sexes obtained from fish 266 of known sex captured during our experiments. We based our criterion on the $10^{\text {th }}$ percentile of 267 the male size distribution $(=6.7 \mathrm{~cm} ; \bar{x} \pm \mathrm{SE}=7.5 \pm 0.11 \mathrm{~cm}, \mathrm{~N}=36)$ and the $90^{\text {th }}$ percentile of the 268 female distribution $(=7.1 \mathrm{~cm} ; \bar{x} \pm \mathrm{SE}=6.7 \pm 0.063 \mathrm{~cm}, \mathrm{~N}=38)$. An intruder was considered to be 269 male if observed on a territory with a female resident and if its estimated size was $\geq 6.7 \mathrm{~cm}$. An 270 intruder was considered to be female if observed on a territory with a male resident and if its size 271 was $\leq 7.1 \mathrm{~cm}$. This rule included some size overlap of the sexes and may therefore include some 272 false assignments. We also tested a more stringent criterion, assigning intruders to be males only 273 if they were $\geq 7.1 \mathrm{~cm}$ and to be females only if they were $\leq 6.7 \mathrm{~cm}$. This criterion necessarily 274 causes less errors of sex assignment but it also causes neglect of data. The results did not change 
qualitatively when we analyzed the data with the more stringent criterion, therefore these

276 analyses are not reported here.

Potential partner: An apparently unmated individual of opposite sex to the resident entering a resident's territory.

281 Winners/losers: The final partner of the resident and winner of territory ownership was defined as the fish present at a territory and interacting with the resident during the terminal check(s) after the end of the release trials. The final winner was always either the 'original' or the 'new partner',

284 and only one of them was present during all final checks; the fish absent during the final checks 285 was considered to be the loser.

'Best matching size': In our study population, partners differed by $11.95 \%$ in total length $(=\bar{x}$; $288 \pm 0.7 \mathrm{SE}, \mathrm{N}=77$; Fig. 1). Therefore we defined a potential partner to have the 'best matching size', 289 if the size difference between the fish was $12 \%$ of the mean size of both fish, with males 290 exceeding females in size.

\section{Analysis}

Statistical analyses were done with SPSS v13.0. All statistical tests are two-tailed. The

294 behavioural data were analysed using non-parametric statistics as they did not fulfil the 295 requirements for parametric testing. For descriptive statistics we give medians and quartiles. In 296 the removal experiment, when we tested the influence of visitor sizes on the residents' behaviour, 297 we used three different measures to describe the size of visitors. The $\alpha$-level of these tests were 298 adjusted by Bonferroni correction. 
For each statistical test we give the respective sample sizes, which are sometimes smaller than the number of performed trials due to missing values. In the partner removal trials, missing values result from the fact that we analysed rates of behaviour per visiting fish, yielding an undefined value when the numerator (the number of fish) was zero. Furthermore, in four trials repairing occurred so fast, that we could not record unpaired fish in these trials.

\section{RESULTS}

\section{Presentation Experiment}

In accordance with our hypotheses about the potential mechanisms underlying size-

311 assortative mating in E. cyanostictus, we expected females to prefer at least one of three from the

312 four categories of males presented to them, either large (L; preference for large size) or

313 intermediately sized (I) males (preference for matching size) over small (S) males, or the own 314 partners (O), if females were able to recognize them. However, we found no significant 315 difference in median distances kept from the tube (Friedman two-way ANOVAs by

316 ranks: $\chi_{3}^{2}=4.36, \mathrm{P}=0.22, \mathrm{~N}=8$; medians [qu.]: L: 13.7 [9.4, 41.2], I:5.5 [0, 30.0], S:8.7 [3.7, 24.4],

317 O: $12.5[6.9,24.4])$, in contact behaviour $\left(\chi_{3}^{2}=3.01, \mathrm{P}=0.39, \mathrm{~N}=8 ; \mathrm{L}: 1.0[0,2.2], \mathrm{I}: 1.0[0.5,7.5]\right.$, $318 \mathrm{~S}: 4.0[1,8.2], \mathrm{O}: 2.0[1.0,3.5])$ or aggression directed towards the tube $\left(\chi_{3}^{2}=4.46, \mathrm{P}=0.22, \mathrm{~N}=9\right.$;

319 L: 0.5 [0, 2.7], I: 40.0 [1.0, 66.0], S: 26.0 [4.0, 106.3], O: $0[0,4.0]$ ) between the four types of 320 presented males. We performed additional analyses to test the ability of females to distinguish 321 their own partner from the unknown males by pooling the data of the latter. Also in these tests the 322 median distances from the tube (Mann-Whitney U-test: $\mathrm{U}=95.5, \mathrm{P}=0.98, \mathrm{~N}=24,8$ ), the frequency 
323 of contact behaviour $(\mathrm{U}=81.5, \mathrm{P}=0.63, \mathrm{~N}=23,8)$ and aggression $(\mathrm{U}=83.5, \mathrm{P}=0.15, \mathrm{~N}=27,9)$ shown

324 towards the fish in the tube did not differ between presentations of the own partner vs. all other 325 males.

\section{Partner Removal and Release Experiments}

Pair-formation after partner removal

After the old partner had been removed, residents paired up again quickly (median time to re-pairing=314 $\min$ [qu.: 102, 370]. Also newly formed pairs were size-assorted (Pearson correlation: $\mathrm{r}=0.62, \mathrm{P}=0.005, \mathrm{~N}=19)$. In 17 trials, residents had only one new partner, while in two trials two new partners occurred (once in succession; once temporarily two males were simultaneously present, each defending half of the territory).

We never observed the actual pair formation directly during this experiment. On five other occasions we witnessed prospective new partners arriving at a territory. By coincidence, in

337 all 5 cases the male had been removed (during 4 male presentation trials with tubes (see above) 338 and during 1 pilot trial done in 2003 for the removal experiment). These cases suggest that the re339 pairing process is very fast (Table 1). In all cases new males arrived soon after removal of the 340 original partner (within 1.5h) and, after first being ignored or attacked by the resident, they were 341 quickly accepted. Already soon after acceptance they behaved as 'partners' (acting together, see

342 'Methods'; in 3 cases the new partners started to defend the territory). In one case, the new male 343 even spawned with the resident female after two days. 
348 Usually, potential partners arrived at the experimental territories sequentially. Compared to the

349 recordings when residents were paired (i.e. before partner removal and after re-pairing), more 350 conspecifics of the opposite sex entered the experimental territories while residents were

351 unpaired (One-sample Chi-square test, male removals: $\chi_{1}^{2}=3.80, \mathrm{P}=0.05, \mathrm{~N}=61$ visitors; female 352 removals: $\chi_{1}^{2}=17.95, \mathrm{P}<0.0001, \mathrm{~N}=69$ visitors), while there was no difference in the frequencies 353 of visiting same-sex fish (male removals: $\chi_{1}^{2}=0.35, \mathrm{P}=0.55, \mathrm{~N}=61$; female removals: $354 \chi_{1}^{2}=0.0096, \mathrm{P}=0.92, \mathrm{~N}=107$; expectations for one-sample test derived from the observation times 355 with or without partner).

Behaviours shown between pair members and non-pair members

Overall, most of the recorded social behaviours among conspecifics were either contact and partner-directed interactions between mates (median [qu.] $=57.8 \%[45.4,69], \mathrm{N}=19$ trials) or aggressive interactions between residents and conspecifics other than their partners $(37.7 \%$ [28.4,

$36151.1])$. Aggression among partners $(0 \%[0,0], \mathrm{N}=19)$, or contact and partner-directed interactions 362 between residents and non-partners $(1.7 \%[0,5.1])$ were rare. aggressive. These interactions made up 20.2\% (=median; qu: 14.1, 27.6) of all aggressive

366 interactions between residents and fish other than their partners. In all analyses presented below 367 we focus only on intraspecific social interactions.

Evidence for partner preference 
373 (1) Behaviour of resident towards potential partners: In general, unpaired residents should be eager to find a new partner, and therefore should seek more contacts with and be less aggressive towards potential partners than paired fish, which usually evict all conspecifics regardless of sex. Accordingly, unpaired residents should show more contact behaviour (S-bend) and less aggression than paired fish towards opposite-sex visitors (potential partners) but not towards same-sex fish. Overall, unpaired residents showed more S-bend per visiting conspecific than paired fish (Mann-Whitney $\mathrm{U}$ test: $\mathrm{U}=160, \mathrm{P}=0.046, \mathrm{~N}=24,20$ ). However, when analysed separately, S-bend rates towards same sex fish $(\mathrm{U}=185, \mathrm{P}=0.46, \mathrm{~N}=22,19)$ or opposite-sex fish $(\mathrm{U}=112.5, \mathrm{P}=0.29, \mathrm{~N}=21,13)$ did not differ between paired and unpaired residents. Rates of aggressive behaviour did not differ between paired and unpaired fish towards visiting conspecifics in general $(\mathrm{U}=176.0, \mathrm{P}=0.28, \mathrm{~N}=23,19)$, or towards the same $(\mathrm{U}=167.5, \mathrm{P}=0.40$, $\mathrm{N}=22,18)$ or the opposite $\operatorname{sex}(\mathrm{U}=148.0, \mathrm{P}=0.76, \mathrm{~N}=21,15)$. By comparing the rates of behaviour using Mann-Whitney U tests, we were able to include all trials in the analysis despite some missing values in the paired data. The results did not differ when using Wilcoxon signed-ranks tests making use of the paired data structure.

(2) Sex differences: Compared to females, males should be more willing to accept potential partners, as it is more difficult for males to pair up again. The Kasakalawe Point population has a male bias of 1.4:1 (Neat \& Balshine 1999, Morley \& Balshine 2002), and males take longer than

392 females to re-pair (Morley \& Balshine 2002; this study, Mann-Whitney U-test: $U=21, P=0.05$, $393 \mathrm{~N}=9,10$ ). Consequently, unpaired males should show a higher frequency of contact behaviour and 394 a lower level of aggression towards potential partners than unpaired females do. However, there 395 was no significant difference between sexes (Mann Whitney U-test, S-bend: U=15.0, $\mathrm{P}=0.24$, $396 \mathrm{~N}=5,8$; aggression: $\mathrm{U}=20, \mathrm{P}=0.54, \mathrm{~N}=5,10$ ) 
After repairing, males were expected to guard new partners more closely than females do.

399 We analysed the sums of 'approaches' and 'follows' (behaviours thought to serve mate guarding;

400 Appendix 1) considering the behavioural rates during those recordings of the removal trials when

401 the resident had a new partner. Contrary to our expectation, resident males showed lower rates of 402 mate guarding than females (Mann-Whitney U-test: $\mathrm{U}=4.5, \mathrm{P}=0.008, \mathrm{~N}=8,6$ ). The mate guarding 403 propensity of new partners towards residents did not differ between sexes $(\mathrm{U}=23.5, \mathrm{P}=0.95$, $404 \mathrm{~N}=8,6)$.

(3) Size-related behaviour by residents: As size-assortative mating is assumed to result from sizebased choice, either relatively large opposite-sex fish or fish of a matching size should be 408 preferred. First we tested if aggression frequencies of unpaired residents depended on the size of 409 potential partners. As the latter differed in size, potential partners are the independent units for 410 this analysis. All correlations between size measures (difference to resident's size, difference to 411 original partner's size, deviation of best match) and aggression frequency were non-significant, 412 both for female ( $\mathrm{N}=19$ dyads) and male residents $(\mathrm{N}=35$ dyads; all $\mathrm{P}>0.1$, Spearman rank 413 correlations). Contact behaviour with potential partners was too rare to be analysed statistically.

Second, we analysed whether interactions between mates after re-pairing depended on 416 size. As in the removal experiment we never observed the pair formation directly, we analysed 417 the first recording after re-pairing as the closest possible measure of this process. Contact 418 behaviour was the only category with sufficiently high frequencies to be quantitatively analysed. 419 Male residents tended to show more S-bends towards females that were larger relative to the size 420 of original partners $\left(\mathrm{r}_{\mathrm{s}}=0.75, \mathrm{P}=0.02, \mathrm{~N}=9\right.$; adjusted $\alpha$-level: 0.017$)$, whereas correlations with the 421 other two size measures, and all correlations between the contact behaviour of female residents 
and male size and were not significant (all $\mathrm{P}>0.1$ ). Combining data of both sexes, again the size

423 differences between new and original partners correlated significantly with S-bend frequency

$424\left(\mathrm{r}_{\mathrm{s}}=0.60 ; \mathrm{P}=0.008, \mathrm{~N}=18\right) . \mathrm{S}-\mathrm{bends}$ shown by new mates towards the residents did not correlate 425 with any of the size measures, neither in males, females or the combined data (all $\mathrm{P}>0.1$ ).

Third, we tested whether the propensity of mate guarding ('approaches' plus 'follows') depends on size. Resident females showed more mate guarding per time towards their new partners when the latter were larger (Spearman rank correlation, difference to female size: $\mathrm{r}_{\mathrm{s}}=0.93, \mathrm{P}=0.001$; difference to original partner's size: $\mathrm{r}_{\mathrm{s}}=0.86, \mathrm{P}=0.006$, all $\mathrm{N}=8$; adjusted $\alpha$ -

431 level: 0.017 ), while mate guarding did not relate to the deviation of best-matching size. None of 432 these comparisons was significant for resident males, nor for male or female new partners (all $433 \mathrm{P}>0.1)$.

(4) Final pair formation: If a mate preference results in the actual choice of a partner, residents

436 faced with a simultaneous choice between original and new partner should exhibit a clear 437 preference for one of the two and, most importantly, the preferred fish should gain partner and 438 territory. To test for a resident's preference during the release trials, we focused on the period 439 before the first encounter of the two same-sex fish, because this first encounter usually decided 440 about territory ownership (see below). When only one partner was present at a territory, the 441 resident always consorted with this fish. Only in six trials, original and new partners were shortly 442 present simultaneously before they first met and started an escalating conflict, which indicates 443 that the chances of the resident to exhibit a preference for either partner in these short periods 444 were very limited. We compared the sum of all contact and partner-directed behaviours of focal 445 residents shown towards or simultaneously with the later winners and later losers of territory 
446 ownership performed during the short periods before the onset of intrasexual aggression. They

447 did not differ significantly (Wilcoxon signed-ranks test: $\mathrm{T}=4.0, \mathrm{P}=0.34, \mathrm{~N}=6$ ).

An anecdotal observation suggests that residents might show preferences but cannot

450 influence the outcome of the encounter between original and new partner and therefore the 451 subsequent pair formation. In one trial, the resident male spawned with its original partner 452 shortly after the latter's release suggesting a preference for this female. Nevertheless, in the end 453 the new partner gained the territory and paired up with the resident male after expelling her 454 mouthbrooding competitor.

(5) Who gains the territory?

457 In 17 trials (89.5\%) we were present when ownership of the experimental territories was decided. 458 In all 17 cases, decisions resulted from actions by one of the two same-sex fish. In 6 trials one of 459 the same-sex fish left stealthily after having stayed hidden in the territory for several min after the 460 release and was never seen again at the territory. In 11 trials territory ownership was determined 461 by aggression between the same-sex fish. The winner of the aggressive encounters always 462 obtained the experimental territories and paired up with the resident (one-sample Chi-square test, $\left.\chi_{1}^{2}=11.0, \mathrm{P}=0.001\right)$. In 9 of the 11 trials $(81.8 \%)$ the winner of the first direct encounter between

464 the two same-sex fish was also the ultimate winner of the territory $\left(\chi_{1}^{2}=4.45, \mathrm{P}=0.035\right)$.

Across the 19 successful trials, size and prior ownership (original or new partner) were 467 unrelated to each other (Fig. 2a; Paired t-test: $\mathrm{t}=-0.62, \mathrm{P}=0.54, \mathrm{~N}=19$ ). Prior ownership did not 468 influence the likelihood to become the final territory owner (Fig. 2b; One-sample Chi-square test: 469 $\left.\chi_{1}^{2}=0.47, \mathrm{P}=0.49, \mathrm{~N}=19\right)$. In contrast, body size strongly determined the likelihood of winning. 
470 With one exception, always the larger same-sex fish became territory owner (Fig. 2c; Paired t471 test, $\mathrm{t}=4.71, \mathrm{P}<0.001, \mathrm{~N}=19$ ). Winners were on average $0.45 \mathrm{~cm}$ (range: $-0.15-1.55 \mathrm{~cm}$ ) or $6.2 \%$ 472 larger than losers.

\section{DISCUSSION}

476 Altogether, four experiments have been done to test for mate preferences in E. cyanostictus, three 477 of them in the field (this study) and one in the lab (Morley 2000). In two of them opposite-sex 478 fish were presented behind transparent barriers either sequentially (tube presentation) or 479 simultaneously (lab experiment, Morley 2000), whereas in the other two tests all fish interacted 480 freely while potential mates were present sequentially (removal experiment) or simultaneously 481 (release experiment). Out of the three experimental manipulations reported here, only the 482 removal experiment provided some evidence for a preference of large-sized partners. Morley's 483 (2000) lab study revealed no size preferences, but rather a preference for more active and less 484 aggressive fish (causes and effects of activity and aggression were not disentangled though).

In our experiment, 'widowed' residents paired up rapidly suggesting that they were not or only marginally choosy, accepting more or less the first intruder arriving. In the release trials, residents did not interfere in the competitive interactions of same-sex fish about territory ownership, and they had no detectable influence on final pair formation. This suggests that mate

490 choice is unlikely to cause size assortment in E. cyanostictus. In contrast, we found evidence that 491 pair formation was determined by a strict competitive advantage of larger fish over smaller ones 492 in direct encounters between same-sex individuals. 
The tube presentations did not reveal evidence for preferences by the focal test fish, not

496 even for the own partners. Therefore, we cannot exclude that the fish presented in the tube were 497 not recognized as possible partners. Moreover, several factors may influence female behaviour, 498 which would obscure possible preferences. These include the behaviour of the presented males, 499 which ranged from motionless to aggressive, and the presence of scale eaters (Perissodus microlepis) or dominant space competitors (Lamprologus moorii) close to the tube in some trials.

In the removal experiment these confounding factors did not exist, but still there were no indications of mate preferences with regard to pairing status, sex or size before re-pairing. More opposite-sex fish entered territories when a resident was single than when it was paired, and unpaired residents showed higher rates of S-bend per visitor than paired fish. The first result does not necessarily reflect an interest of visitors to settle in a territory. Visitors may have simply

507 taken advantage of the absence of one of the territory owners by using the territory for 508 trespassing or feeding. The increased contact rate by residents towards visitors, however, might 509 indicate a propensity to re-mate. After re-pairing two results indicate that residents responded to 510 their new partners' sizes. (i) Residents showed more S-bends when the new partner was larger 511 relative to their own size or to the size of their original mate; and (ii) resident females showed 512 more mate guarding the larger new partners were. Although these relationships became apparent 513 only after re-pairing, they might point towards a weak preference for large-sized partners.

516 preference function and 'choosiness', i.e. the effort an individual is prepared to invest in mate 517 assessment. While there are some indications that the preference function of residents ranked 518 large individuals higher, we are lacking any evidence for choosiness. (i) In most trials, time to re519 pairing was too short to allow for extensive assessment of the range of possible partners. (ii) In 
520 five cases where we observed the entire process of a conspecific arriving at a territory and being

521 accepted (Table 1), these fish were almost immediately tolerated after the first contact between 522 resident and incoming fish. In three of the five cases the resident was first aggressive towards the 523 incoming fish before switching quickly to partner-directed behaviour. (iii) Residents did not 524 interfere in the contest between original and new partners, and readily accepted the winners as 525 their partners.

\section{Are the Incoming Fish Tolerated by Widowed Residents Really New Partners?}

We propose that this is the case. First, none of the new partners, which won the contest

529 with the original owner, had left the territory at our checks done until 2-37 d after the end of the 530 release tests. Second, regular long-term checks of 70 territories showed that single territory 531 owners do not occur (B. Taborsky, unpub. data). E. cyanostictus forms long-term pair-bonds and 532 partners stay together on average for 226 days (B. Taborsky et al., in prep). Females need to have 533 a partner around for joint brooding at any time as they reproduce year-round. It is unlikely that 534 they would tolerate fish to stay in their territory if they could not breed with them, because of 535 competition for food and shelter. For the same reason, males should only tolerate prospective 536 spawning partners.

Where do New Partners Come from?

One might argue that re-pairing is quick and preferences are difficult to detect, because

540 the prospective partners know each other already from previous interactions. While this cannot be 541 completely excluded, usually new partners are at least not recruited from directly adjacent 542 territories. The latter case occurred only once during a pilot trial in 2003 . The two involved 543 females, the experimental widow and the current partner of a male that tried to switch between 
544 neighbouring territories engaged in extensive mouthfights. In no other trial we ever saw such

545 fights between same-sex neighbours.

From partner removal trials done in E. cyanostictus in a different experimental context

548 (Taborsky, B., Guyer, L. \& Demus, P., unpub. data), we know that new partners can be recruited

549 from distances exceeding $10 \mathrm{~m}$. Our data indicate that potential new partners available to 550 experimentally widowed fish span the full spectrum of body sizes of adult territorial fish. In a $55120 \times 20 \mathrm{~m}$ area we detected 53 territorial pairs exhibiting a size variation between $6.5-8.5 \mathrm{~cm}$ in 552 males and 6.0-7.5 $\mathrm{cm}$ in females (Taborsky, B., Guyer, L. \& Demus, P., unpub. data), and in 553 addition, a population of floating individuals is present in our study area (Morley 2000).

\section{Why is Mate Choice absent despite weak Size Preferences?}

Mate choice is influenced not only by preference, but also by mate availability and the costs of choice (Jennions \& Petrie 1997). When the costs of choice are high, choosiness for

558 partners may be reduced, for instance when predators are present (reviewed in Magnhagen 1991,

559 Jennions \& Petrie 1997). In E. cyanostictus, the predominant risk is the loss of the territory and 560 the resources it provides due to intense space competition. Virtually all lake bottom area at our 561 study site was occupied by territories of E. cyanostictus or one of their space competitors. 562 Experimentally-created, vacant territories were quickly taken over by neighbouring pairs (Morley $563 \&$ Balshine 2002). Furthermore, $14.6 \%$ of a total of 48 E. cyanostictus experimentally widowed 564 by Morley \& Balshine (2002) and by us left their territories within 5 days after partner removal 565 without having re-paired. In species that defend all-purpose territories, the loss of a partner may 566 be detrimental if one individual alone is not able to defend the territory against intruders. Hence 567 quick re-pairing may be crucial for singletons in order to keep the territory, which provides food, 568 shelter and breeding opportunities. Likewise, in the absence of vacant space, incoming 
conspecifics should have a strong interest to pair up quickly to obtain a territory and a partner.

This should be true if vacancies open up only rarely, which is likely to be the case, and it should especially hold for male floaters, which exist in excess in our population. Rather than being driven by mate choice this system appears to represent 'opportunistic' monogamy, where having any partner is highly advantageous over having no partner. Strong competition for breeding sites appears to override the importance of mate quality also in a monogamous, biparental bird, the guillemot (Uria aalge, Jeschke et al. 2007). We would like to stress that we were able to detect opportunistic mating behaviour because we performed our trial in the presence of natural competitor densities and the possibility of direct interactions between prospective partners. It would have been impossible to simulate natural competitor densities and the entire spectrum of potential partners in a controlled laboratory situation.

\section{How can Size-Assortative Mating arise in the Absence of Active Choice?}

Given the importance of territory possession and the strictly size-dependent potential to win competitive encounters, it is conceivable that larger singleton floaters expel smaller, physically inferior territory owners, thereby forcing the original resident pair to divorce. 'Forced divorce' (sensu B. Taborsky \& M. Taborsky, pers. comm. with Choudhury 1995), when pair bonds are terminated by intruders, appears to be the commonest source of divorce in a number of monogamous bird species (Williams \& McKinney 1996, Taborsky \& Taborsky 1999, Heg et al. 2003, Jeschke et al. 2007) living at densities at or near their carrying capacity. Each expulsion of a resident naturally creates a new singleton, hence forced divorce might result in suites of expulsions and new pair formations.

While it is possible that frequent replacements of smaller territory owners by larger samesex conspecifics may generate a tendency for size assortment, it is unlikely that this mechanism 
suffices to generate the strong correlation between sizes of mating partners as observed in $E$.

595 cyanostictus. Moreover, the presence of size preferences after re-pairing has happened suggests 596 that there are fitness effects of partner size. The effort of an active mate choice for size may not 597 be necessary, however, if a different, simpler mechanism has similar effects. Habitat choice, a 598 common factor promoting non-random settlement in animals (e.g. Rodenhouse et al. 1997), is a 599 good candidate for an alternative mechanism, as in E. cyanostictus territories vary considerably in 600 habitat quality. If larger fish dominate the access to high-quality territories as suggested by our 601 results, size-assortative mating may result as a by-product of habitat preferences (B. Taborsky, L. 602 Guyer \& P. Demus, unpub. data).

\section{Conclusions}

Even in species with long-term monogamy pairs may be formed opportunistically rather 606 than by mate preference, if the presence of a pair partner is crucial for territory maintenance. 607 Intra-sexual competition combined with a size-dependent competitive advantage had been 608 proposed to promote size-assortative mating caused by mate choice for large size. Here we 609 showed that it can act also in the absence of active mate choice, although the evolution of strong 610 size assortment requires probably additional mechanisms.

\section{Acknowledgments}

614 We thank M. Cicciarello for help with data collection, Dr. H. Phiri and R. Shapola for logistic 615 support at the Fisheries Department in Mpulungu, Zambia, and the Ministry of Agriculture and 616 Co-operatives of Zambia for the permission to perform this study. B.T. acknowledges financial 617 support by the Forschungsstiftung, University of Bern (48/2003), the Austrian Science Fund, 
618 FWF (P18647-B16) and the Swiss National Foundation, SNF (grant 3100A0-111796) during

619 different stages of this study.

\section{References}

Alatalo,R.V., Höglund,J., Lundberg,A. \& Sutherland,W.J. 1992. Evolution of black grouse leks females preferences benefit males in larger leks. Behavioral Ecology 3, 53-59.

Arak,A. 1983. Male-male competition and mate choice in anuran amphibians. In: Mate Choice (Ed. by P.Bateson), pp. 181-210. Cambridge: Cambridge Univ. Press. (Coleoptera, Chrysomelidae). Behavioral Ecology and Sociobiology 33, 151-157.

629 Choudhury,S. 1995. Divorce in birds - A review of the hypotheses. Animal Behaviour 50, 413630429.

631 Crespi,B.J. 1989. Causes of assortative mating in arthropods. Animal Behaviour 38, 980-1000.

632 Cruz,R., Carballo,M., Conde-Padin,P. \& Rolan-Alvarez,E. 2004. Testing alternative models for sexual isolation in natural populations of Littorina saxatilis: indirect support for by-product ecological speciation? Journal of Evolutionary Biology 17, 288-293.

635 Delestrade,A. 2001. Sexual size dimorphism and positive assortative mating in Alpine Choughs 636 (Pyrrhocorax graculus). Auk 118, 553-556.

637 Gagliardi-Seeley,J.L. \& Itzkowitz,M. 2006. Male size predicts the ability to defend offspring in 638 the biparental convict cichlid Archocentrus nigrofasciatus. Journal of Fish Biology 69, 12396391244.

640 Grüter,C. \& Taborsky,B. 2004. Mouthbrooding and biparental care: an unexpected combination, 641 but male brood care pays. Animal Behaviour 68, 1283-1289.

642 Grüter,C. \& Taborsky,B. 2005. Sex ratio and the sexual conflict about brood care in a biparental 643 mouthbrooder. Behavioral Ecology and Sociobiology 58, 44-52.

644 Harari,A.R., Handler,A.M. \& Landolt,P.J. 1999. Size-assortative mating, male choice and female 645 choice in the curculionid beetle Diaprepes abbreviatus. Animal Behaviour 58, 1191-1200.

646 Härdling,R. \& Kokko,H. 2005. The evolution of prudent choice. Evolutionary Ecology Research $647 \quad 7,697-715$.

648 Heg,D., Bruinzeel,L.W. \& Ens,B.J. 2003. Fitness consequences of divorce in the oystercatcher, 649 Haematopus ostralegus. Animal Behaviour 66, 175-184. 
650 Helfenstein,F., Danchin,E. \& Wagner,R.H. 2004. Assortative mating and sexual size dimorphism 651 in Black-legged Kittiwakes. Waterbirds 27, 350-354.

652 Jennions,M.D. \& Petrie,M. 1997. Variation in mate choice and mating preferences: a review of 653 causes and consequences. Biological Reviews 72, 283-327.

654 Jeschke,J.M., Wanless,S., Harris,M.P. \& Kokko,H. 2007. How partnerships end in guillemots 655 Uria aalge: chance events, adaptive change, or forced divorce? Behavioral Ecology 18, 460-466.

656 Johannesson,K., Rolan Alvarez,E. \& Ekendahl,A. 1995. Incipient reproductive isolation between 657 two sympatric morphs of the intertidal snail Littorina saxatilis. Evolution 49, 1180-1190.

658 Kokko,H. \& Johnstone,R.A. 2002. Why is mutual mate choice not the norm? Operational sex 659 ratios, sex roles and the evolution of sexually dimorphic and monomorphic signaling. 660 Philosophical Transactions of the Royal Society, Series B, 357, 319-330.

661 Kolm,N. 2001. Females produce larger eggs for large males in a paternal mouthbrooding fish. 662 Proceedings of the Royal Society of London Series B-Biological Sciences 268, 2229-2234.

663 Kolm,N. 2002. Male size determines reproductive output in a paternal mouthbrooding fish. 664 Animal Behaviour 63, 727-733.

665 MacDiarmid,A.B. \& Butler,M.J. 1999. Sperm economy and limitation in spiny lobsters. 666 Behavioral Ecology and Sociobiology 46, 14-24.

667 Magnhagen,C. 1991. Predation risk as a cost of reproduction. Trends in Ecology \& Evolution 6, $668 \quad 183-186$.

669 Michiels,N.K., Hohner,A. \& Vorndran,I.C. 2001. Precopulatory mate assessment in relation to 670 body size in the earthworm Lumbricus terrestris: avoidance of dangerous liaisons? Behavioral 671 Ecology 12, 612-618.

672 Miyashita,T. 1994. Size-related mating and mate guarding in the orb-web spider Nephila clavata 673 (Aranae, Aranaidae). Journal of Insect Behavior 7, 289-296.

674 Morley,J.I. 2000. Intraspecific competition and monogamy in the cichlid fish, Eretmodus 675 cyanostictus. PhD thesis, University of Cambridge.

676 Morley,J.I. \& Balshine,S. 2002. Faithful fish: territory and mate defence favour monogamy in an 677 African cichlid fish. Behavioral Ecology and Sociobiology 52, 326-331.

678 Neat,F.C. \& Balshine-Earn,S. 1999. A field survey of the breeding habits of Eretmodus 679 cyanostictus, a biparental mouthbrooding cichlid in Lake Tanganyika. Environmental Biology of 680 Fishes 55, 333-338.

681 Olafsdottir,G.A., Ritchie,M.G. \& Snorrason,S.S. 2006. Positive assortative mating between 682 recently described sympatric morphs of Icelandic sticklebacks. Biology Letters 2, 250-252.

683 Olsson,M. 1993. Male preference for large females and assortative mating for body size in the 684 sand lizard (Lacerta agilis). Behavioral Ecology and Sociobiology 32, 337-341. 
685 Otronen,M. 1993. Size assortative mating in the yellow dung fly Scatophaga stercoraria.

686 Behaviour 126, 63-76.

687 Preston,B.T., Stevenson,I.R., Pemberton,J.M., Coltman,D.W. \& Wilson,K. 2005. Male mate 688 choice influences female promiscuity in Soay sheep. Proceedings of the Royal Society B 272, $689365-373$.

690 Ridley,M. 1983. The Explanation of Organic Diversity: the Comparative Method and 691 Adaptations for Mating. Oxford: Clarendon Press.

692 Riechert,S.E. \& Johns,P.M. 2003. Do female spiders select heavier males for the genes for 693 behavioral aggressiveness they offer their offspring? Evolution 57, 1367-1373.

694 Rodenhouse,N.L., Sherry,T.W. \& Holmes,R.T. 1997. Site-dependent regulation of population 695 size: A new synthesis. Ecology 78, 2025-2042.

696 Roff,D.A. 1992. The Evolution of Life Histories. New York: Chapman \& Hall.

697 Rowe,L. \& Arnqvist,G. 1996. Analysis of the causal components of assortative mating in water 698 striders. Behavioral Ecology and Sociobiology 38, 279-286.

699 Shine,R., O'Connor,D., Lemaster,M.P. \& Mason,R.T. 2001. Pick on someone your own size: 700 ontogenetic shifts in mate choice by male garter snakes result in size-assortative mating. Animal 701 Behaviour 61, 1133-1141.

702 Steinegger,M. \& Taborsky,B. 2007. Asymmetric sexual conflict over parental care in a biparental 703 cichlid. Behavioral Ecology and Sociobiology 61, 933-941.

704 Taborsky,B. \& Taborsky,M. 1999. The mating system and stability of pairs in kiwi Apteryx spp. 705 Journal of Avian Biology 30, 143-151.

706 Vreys,C. \& Michiels,N.K. 1997. Flatworms flatten to size up each other. Proceedings of the 707 Royal Society of London, Series B 264, 1559-1564.

708 Williams,M.J. \& McKinney,F. 1996. Long-term monogamy in a river specialist - the Blue Duck. 709 In: Partnerships in Birds: the Study of Monogamy (Ed. by J.M.Black), pp. 73-90. Oxford: Oxford 710 University Press.

711 Wong,B.B.M. \& Candolin,U. 2005. How is female mate choice affected by male competition? 712 Biological Reviews 80, 559-571.

713

714

715 716

\section{Appendix 1}

Social behaviours, which were observed during the 15-min behavioural recordings and recorded as frequencies (c.f. also Morley 2000, Appendix C for a description of some of these behaviours) 


\section{Contact behaviour}

721 'S-bend': A fish curves its body into an 'S' shape in front of a conspecific. This is the second most prominent behavioural category within the social behaviours (531 times observed; only aggressive behaviour was observed more often; $\mathrm{N}=603$ ), while all remaining social behaviour types were observed rarely. As S-bend is mostly shown towards the partner and also occurs before and during spawning, it has been classified previously as courtship behaviour (Morley 2000). However, the fact that it occurs in peaceful, neutral and aggressive contexts suggests that its function is much broader. Therefore, an analysis of the function of this behaviour was required, and we analysed the context of each of the 531 recorded Sbends. Overall, S-bends were shown about 6 times more often towards partners than towards visitors (3.72 and 0.61 times per 15-min recording, respectively). Partners either showed no response or did an S-bend simultaneously. Occasionally, unilateral or mutual S-bends between partners occurred within a behavioural sequence containing also S-shake, circling, following or approaches (see descriptions below). Between partners, S-bend never occurred together with aggression. When the conspecific was not a partner, in 55.3\% S-bend was not accompanied by any other behaviours, while in $44.7 \%$ of the cases it was immediately followed by aggression (44.7\%), usually by the individual performing the S-bend $(87.5 \%$ of 42 cases with aggression). Only 5 times (5.3\%) S-bend towards a conspecific was directly followed by partner-directed behaviour.

S-bends directed towards visitors occurred about three times more often when only a single resident occupied the territory (i.e. during the removal phases before re-pairing; $\mathrm{N}=0.59$ per visitor, as compared to 0.19 when a partner was present) and residents were more likely to show an S-bend towards visitors (63.6\%) than the other way round (36.4\%). Overall, S-bends were shown at similar rates by male and female residents $(0.19$ and 0.21 times per 
visitor, respectively), whereas among visitors only males showed S-bends. Furthermore, Sbends were shown at similar rates towards both sexes (towards a male: 0.30 times per

746 resident-visitor dyad; towards a female: 0.25 times per dyad). Analysing both sexes involved in a dyad, S-bends occurred most often between males and females ( 0.41 times per dyad) and between males ( 0.32 times per dyad), while they were observed only rarely between females (0.08 times per dyad).

In summary, S-bend occurs predominantly between partners, where it occurs in combination with partner-directed behaviour or in 'neutral' interactions (=no obvious detectable context). When shown towards non-partners, there are no obvious differences regarding the sex by which and towards which it is shown, and the context is usually either aggressive or neutral. From these observations and the fact that it occurs so frequently, we conclude that S-bend serves a very general contact function. It probably serves to reveal the own presence and identity, and at the same time to collect information about the identity and intention of the recipient. As it is usually shown in front of a (moving) conspecific, it may also serve to stop possible intruders early to proceed on their way into the territory. In a metaphorical sense, we think this behaviour is a combination between an exclamation mark and a question mark, i.e. it does not convey a specific meaning, but serves to catch attention

\section{Partner-directed behaviour}

764 We classified the behaviours in this section as 'partner-directed', as they occur almost exclusively 765 between pair members. Over all recordings, only 8 times a behaviour of this category was 766 directed to a non-partner. 
767 'S-shake': Similar to S-bend, but at the same time the fish shakes it whole body with varying 768 intensity. Partners often show this behaviour simultaneously while positioned in parallel. S769 shake has never been observed in an aggressive context.

770 'Circling': Partners turn around each other in tight circles, each following the other. In some cases 771 they circle while one fish (usually the female) points with its head towards the flank of the 772 other fish (usually the male) ('T-position'). When in T-position, often the first fish directs 773 bites towards the flank of the second fish but without actual body contact ('intentional bite'). 774 These behaviours are an intensive form of courtship, which also directly precede spawning.

775 'Approach': A fish swims directly towards its partner at a moderate speed; the approach is not followed by a threat, a chase or a fight. After an approach, usually the two involved fish stayed together in close proximity for some time.

'Follow': A fish follows a conspecific approximately at constant distance and at a moderate speed; the behaviour is not followed by a threat, a chase or a fight.

By 'Approach' and 'Follow' fish attain or maintain a close distance to their partner, suggesting that these behaviours may function as mate guarding.

'Feeding together': Pair partners feed at close proximity (up to $30 \mathrm{~cm}$ distance), usually positioned parallel to each other. We counted continuous bouts of this behaviour, which may consist of a few to several tens of bites in quick succession. Accordingly, their length is highly variable. This behaviour occured only between partners and it might be an important component of mate guarding. We did not assign it to the mate guarding behaviours, however, as obviously its main function is food uptake; it was hence not included in our statistical analyses of social behaviour, but it was part of our criterion to indentify pairs (see 'Methods'). 
791 'Restrained attack': A moderately fast forward movement towards another fish, which is 792 accompanied by spreading the unpaired fins. The movement is stopped before the opponent is 793 reached.

794 'Overt attack': A fish approaches another fish at high speed, obviously trying to hit it. In contrast 795 to a 'chase', the focal fish does not continue to follow its opponent once the latter flees from 796 the attacker.

797 'Chase': One fish follows another fish at high speed, while the other fish is fleeing. If the other 798 fish is reached, the chaser directs a bite towards its opponent's tailfin.

799 'Bite': One fish bites another fish anywhere on the body.

800 'Pseudo-mouthfight': Two fish swim head to head back and forth while maintaining a constant 801 distance between each other's heads. This behaviour is frequently seen between territorial 802 neighbours close to their common territory border.

803 'Mouthfight': Two fish fight by locking their jaws and wrestling. 
Table 1: Summary of five cases where males were observed arriving and being accepted at territories by female residents after the

\begin{tabular}{|c|c|c|c|c|c|c|c|}
\hline date & $\begin{array}{c}\text { type of } \\
\text { experiment }\end{array}$ & $\begin{array}{l}\text { female's response } \\
\text { before accept. }\end{array}$ & pair-typical behaviour ${ }^{2}$ & $\begin{array}{c}\text { male } \\
\text { defends? }\end{array}$ & $\begin{array}{l}\text { time to } 1^{\text {st }} \\
\text { contact }^{4}\end{array}$ & $\begin{array}{l}\text { time to } \\
\text { accept. }^{5}\end{array}$ & $\begin{array}{l}\text { time to } \\
\text { leaving }\end{array}$ \\
\hline 25.10 .03 & male removal & aggression & mutual S-bend & yes & 20 & 20 & stayed $^{\mathrm{a}}$ \\
\hline 4.10 .05 & male presentation & ignores male & feed together, approach, follow & no & 51 & 5 & 25 \\
\hline 6.10 .05 & male presentation & weak aggression & mutual S-bend & yes & 75 & $1-5$ & stayed \\
\hline 7.10 .05 & male presentation & aggression & feed together & yes & 82 & 7 & $10^{\mathrm{b}}$ \\
\hline 15.10 .05 & male presentation & $\begin{array}{l}\text { pair-typical } \\
\text { behaviour }\end{array}$ & mutual S-bend & $\begin{array}{l}\text { not } \\
\text { recorded }\end{array}$ & 53 & 0 & stayed \\
\hline
\end{tabular}

${ }^{1}$ Initial response of female towards the new male before both engaged in 'pair-typical' behaviour

$807{ }^{2}$ Behaviours shown that are typical for pair members (for details see definition 'Pair' in 'Methods')

$808{ }^{3}$ Was the new male aggressive against conspecifics within the territory?

$809{ }^{4}$ Time interval after removal of original partner until first contact and interaction between resident female and new male

$810{ }^{5}$ Time interval from first contact to onset of pair-typical behaviour ('acceptance')

$811{ }^{6}$ Time interval from acceptance of new male to time male left again, if it left at all; 'stayed' indicates that male stayed at least until end

812 of the observation period (i.e. 2 days in male removal trial and 2-3 hours in male presentation trials).

813 a on day 2 after its arrival the new male spawned with the resident female

$81{ }^{\mathrm{b}}$ male left territory while we caught the female, probably because of disturbance 


\section{Figure Legends}

Fig. 1: Correlation between the total lengths of male and female pair partners of unmanipulated pairs in Kasakalawe Bay (Pearson correlation: $\mathrm{r}=0.73, \mathrm{P}<0.001, \mathrm{~N}=77$ ). The dashed line denotes equal sizes of pair members. Males are usually larger than their female partners (almost all data points are below the dashed line), and relative size differences between pair members increase linearly with increasing absolute size.

Fig. 2: Results of the release phases of 19 experimental trials; (a) mean $\pm \mathrm{SE}$ total lengths of original (black) and new (grey) partners; (b) number of original (black) vs. new (grey) male and female partners that took over the experimental territories and stayed until the end of the experiment (='winners'); (c) mean \pm SE total lengths of 'winners' (black) and 'losers' (grey). 


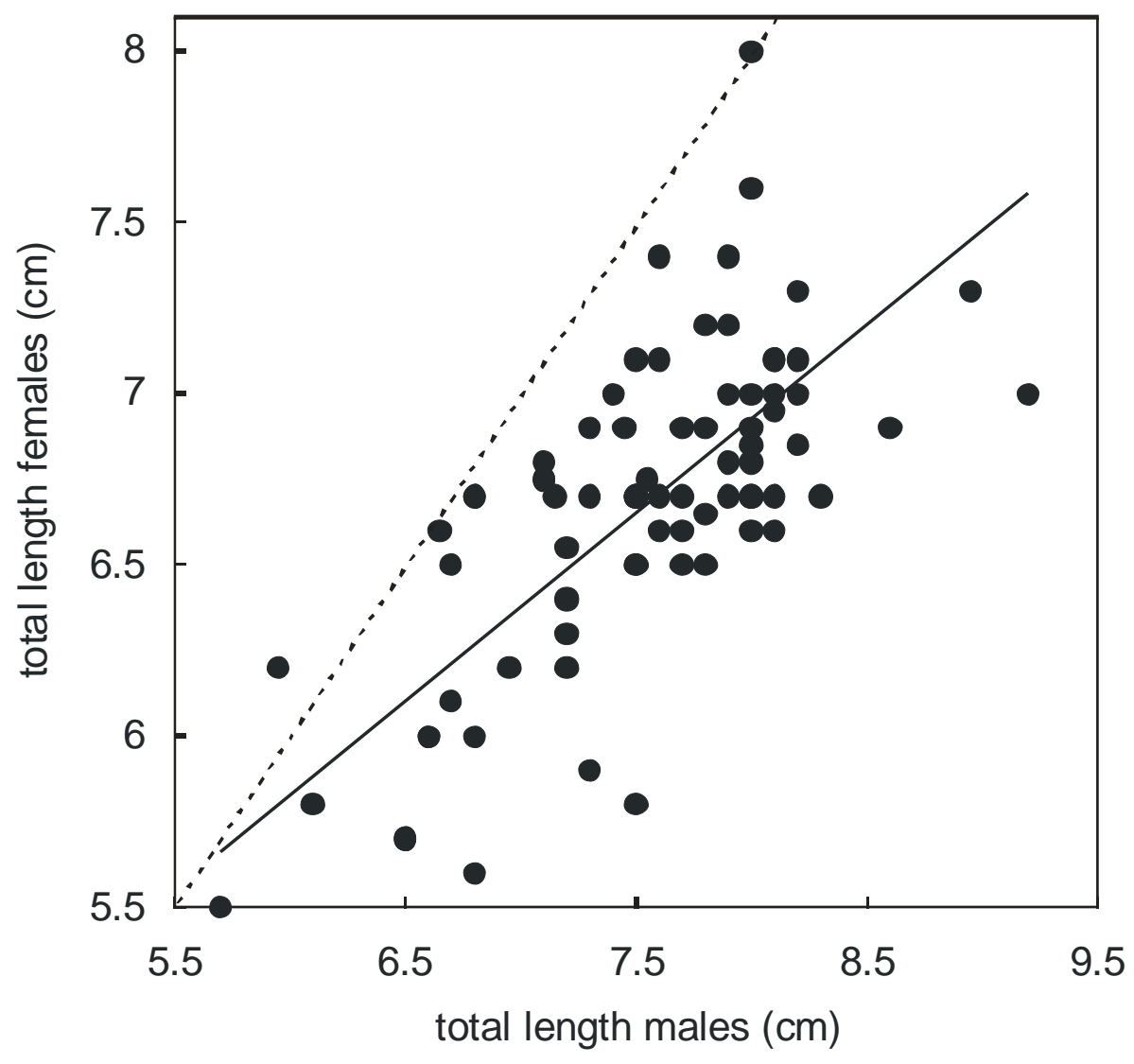

Figure 1 
(a)

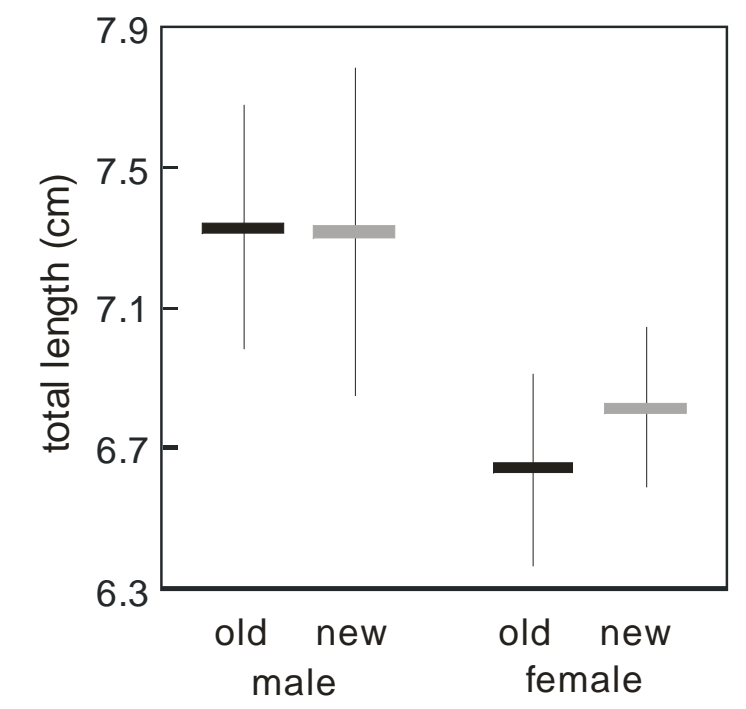

(b)

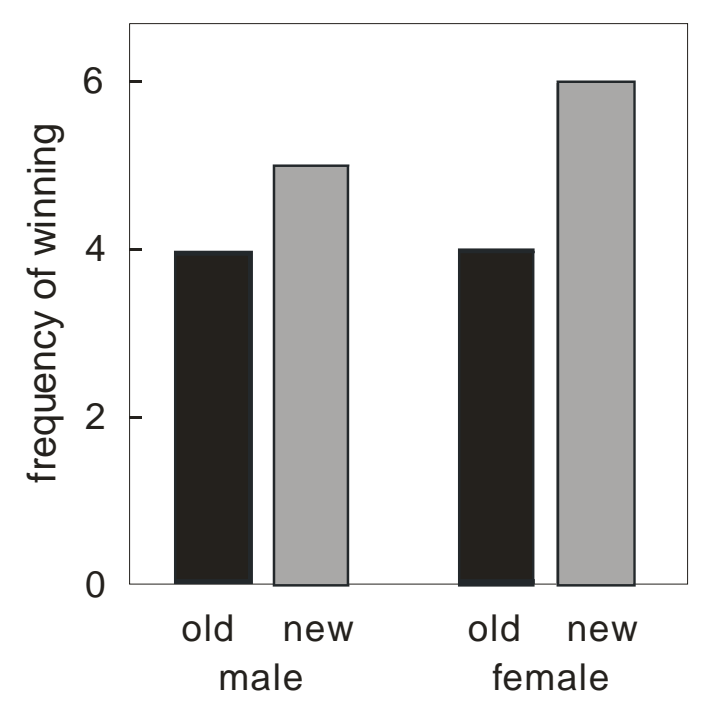

(c)

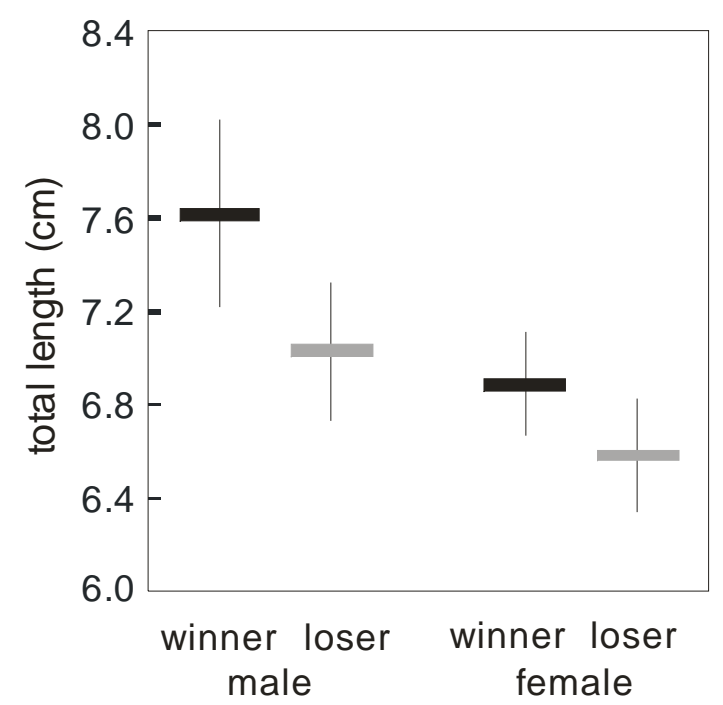

Figure 2 